\title{
Are we overestimating the permanence of cellulose triacetate cinematographic films? A mathematical model for the vinegar syndrome
}

\author{
Ida R. Ahmad ${ }^{\mathrm{a}}$, Deborah Cane ${ }^{\mathrm{b}}$, Joyce H. Townsend ${ }^{\mathrm{b}}$, Cristian Trianac ${ }^{\mathrm{c}}$, Luca Mazzeid,*, Katherine \\ Curran ${ }^{\mathrm{a}, *}$ \\ ${ }^{a}$ Institute for Sustainable Heritage, University College London, Central House, 14 Upper Woburn Place, \\ London WC1H ONN, United Kingdom \\ ${ }^{b}$ Tate Britain, Millbank, Westminster, London SW1P 4RG, United Kingdom \\ c Process Systems Enterprise, 26-28 Hammersmith Grove, Hammersmith, London W6 7HA, United \\ Kingdom \\ ${ }^{d}$ Department of Chemical Engineering, University College London, Torrington Place, London WC1E TJE, \\ United Kingdom
}

*Corresponding authors: k.curran@ucl.ac.uk, l.mazzei@ucl.ac.uk

\section{Abstract}

Among the earliest signs of degradation in cellulose triacetate cinematographic films is the generation of acetic acid due to hydrolytic deacetylation of the polymer, marked by an increase in the acidity of the films and emissions of acetic acid leading to a characteristic vinegar odour. We propose a mathematical model for predicting the onset of the vinegar syndrome which accounts for the autocatalytic effect of acetic acid on the deacetylation reaction. Model parameters are estimated from previously published experimental data from other research groups. These show free acidity changes in cellulose triacetate films subjected to accelerated ageing at temperatures of $70-100{ }^{\circ} \mathrm{C}$. The model is validated against a different set of previously published experimental data of cellulose triacetate films aged at $21{ }^{\circ} \mathrm{C}$ and $35{ }^{\circ} \mathrm{C}$, at 20,35 and $50 \%$ relative humidity. The model demonstrates good quantitative agreement with the published experimental data. Predictions of film permanence at lower temperatures, similar to those present in the archives in which the films are typically stored, are made and compared with the predictions of film conservation guidelines. The results indicate that film permanence may be overestimated by existing guidelines, which do not account for autocatalysis in their modelling of the deacetylation rate. Our results suggest that cold storage, a common film conservation strategy, may be less effective at inhibiting degradation than previously thought. As cold storage typically requires film to be kept in confined spaces with limited air movement, conditions which promote autocatalysis, the inclusion of autocatalysis in our model is highly applicable to simulating this environment.

Keywords: cellulose acetate; acetic acid; cinematographic films; kinetics; autocatalysis; mathematical modeling; lifetime prediction; Arrhenius; hydrolysis; deacetylation

\section{Introduction}

Motion picture films recorded on cellulose triacetate base demand significant attention for their historical and artistic value, prevalence in collections and instability. Also known as 'safety film', cellulose triacetate (CTA) came into use in the 1950s as an alternative film base material to cellulose nitrate which, though widely used, was both unstable and highly flammable $(1,2)$. However, CTA films also suffer from inherent instability. It has been extensively observed that one of the first signs of degradation in CTA films is emissions of acetic acid; this process is nicknamed 'vinegar syndrome' owing to its characteristic odour of acetic acid (3-6). The issue is sufficiently infamous that at least ten 
patent applications dealing with film preservation mention the problem, if not claiming to tackle it directly (7-16). Typically, other changes in the film properties will occur after the vinegar syndrome has been initiated. These include reduction in tensile strength or toughness due to degradation of the polymer (embrittlement), buckling of emulsion away from the base layer (shrinkage and channelling), and surface deposits caused by the migration of plasticiser (crystals or bubbles) (17-21). Emissions of acetic acid from degraded CTA films have also been shown to induce vinegar syndrome in undegraded films stored nearby, lending cellulose acetate its reputation as a 'malignant' plastic $(22,23)$. More recently, cellulose acetate has been studied due to its potential as a degradable polymer $(24,25)$. An understanding of its degradation is therefore of relevance, not only to those managing heritage collections but also for those looking to develop more sustainable materials.

Cellulose acetate is a derivative of the naturally-occurring polymer cellulose, which is produced in plants (26). In cellulose acetate, the monomers are anhydroglucose units (AGUs) which are substituted by up to three acetyls $\left(\mathrm{CH}_{3} \mathrm{CO}\right)$ at carbon positions 2, 3 and 6 (Figure 1). The degree of substitution (DS) is used to describe the average degree of acetylation in cellulose acetate (27). DS impacts the properties of cellulose acetate, for example its miscibility in different solvents; consequently, it is produced in a range of DS which reflects its use in diverse products from cigarette filters to hair combs (27-29). This paper concerns cellulose triacetate cinematographic (or photographic) film base, which is substituted to a specification of 2.7-3.0 (28). This decreases as deacetylation progresses.

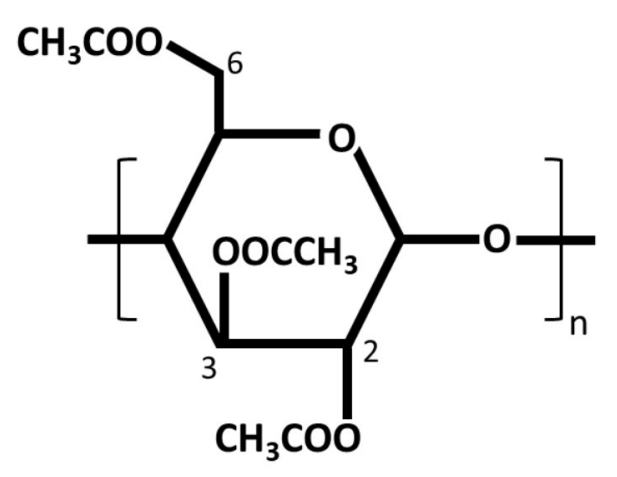

Fig. 1: Chemical structure of CTA monomer. In this example, the DS is three, because there are three acetyl $\left(\mathrm{CH}_{3} \mathrm{O}\right)$ groups.

Deacetylation of CTA occurs by the reaction of water $\left(\mathrm{H}_{2} \mathrm{O}\right)$ with a bound acetyl group (ROAc), resulting in hydroxyl substitution (ROH) and acetic acid (HOAc). In this notation, OAc represents $\mathrm{CH}_{3} \mathrm{COO}$ (Ac is short for acetyl) and $\mathrm{R}$ represents the rest of the polymer (30). The chemical reaction is:

$$
\mathrm{ROAc}+\mathrm{H}_{2} \mathrm{O} \rightarrow \mathrm{HOAC}+\mathrm{ROH}
$$

Emissions with a vinegar-like odour due to the production of acetic acid are typically the first sign of degradation in CTA film, and are considered an obvious warning signal to professional conservators and private collectors alike, indicating more rapid and severe degradation to follow (21). While acidic film with no other visible signs of degradation has been observed, very badly degraded film is nearly always highly acidic (31).

In previous studies, the extent of vinegar syndrome in CTA film has been studied using measurements of the free acidity of the film. Free acidity, determined by the millilitres of $0.1 \mathrm{M} \mathrm{NaOH}$ required to neutralise one gram of film base, is considered the most sensitive indicator of degradation in CTA film (31). Accelerated ageing experiments reveal that the free acidity in CTA film proceeds with an induction phase, where little change is observed over a period of time, followed by the so-called initiation of the vinegar syndrome, where the rate of change in free acidity increases dramatically (17). 
At the initiation point, the deacetylation reaction is said to become autocatalytic, as increasing quantities of acetic acid become available to catalyse the reaction. According to conservation guidelines, a rule of thumb is that the reaction becomes autocatalytic at a free acidity of 0.5 (31). However, no scientific explanation has been proposed to explain why the acid-catalysed mechanism should not occur as long as there is acid present; nor why a free acidity of 0.5 is the characteristic point at which the dominant mechanism changes to acid-catalysed. A later analysis of the same published accelerated ageing data which was argued by the original authors to show this "autocatalytic point" found no evidence of a distinct change at 0.5 acidity (32).

Previously, kinetic models of deacetylation in CTA film had been developed with the motivation to predict the time until the onset of the vinegar syndrome under different conditions of temperature and relative humidity $(\mathrm{RH})(33)$. These models assumed a constant rate of reaction during the induction phase, and did not take into account the catalytic effect of acetic acid $(17,21)$.

In this paper, we present a dynamical model which accounts for autocatalysis. The analytical solution of the model was used to estimate kinetic parameters from published data. These parameters were implemented in the model, which was then solved to make predictions which were compared with a different set of published data. Finally, the model predictions of film permanence were compared with the values published by film conservation guidelines, which do not take into account autocatalysis. The confined enclosures typically used to store films inhibit the release of acetic acid from the films, facilitating autocatalysis, so our model is able to quantitatively predict the maximum risk that this poses to the film stability. This paper therefore provides important guidance to those responsible for valuable CTA materials in heritage collections. More broadly, the approach taken here could also be used to simulate outdoor conditions, relevant to studying the persistence of cellulose acetate in the environment.

\section{Methods}

The practical scenario we modelled is one in which the film is stored in an air-tight enclosure made of a material that does not interact with any of the compounds in the film. The film, which can be a roll or strip, occupies most of the enclosed volume.

Two different experimental procedures, carried out by other researchers, were considered to fit this practical scenario. In both, the film was first moisture-conditioned, so that the initial moisture content was in equilibrium with the temperature and $\mathrm{RH}$ of the environment in which it was placed.

In the first procedure (bag method), following moisture-conditioning, strips of film were incubated in two heat-sealed aluminium foil-polyethylene bags (17). Air was removed from the bags prior to sealing in order to maintain a high film-to-air volume ratio.

In the second procedure (can method), rolls of film were incubated in taped metal cans (34). Experiments using either of these procedures were found to be in agreement with one another in terms of the measured free acidity, supporting our treatment of the two procedures as equivalent (22).

To model this scenario, we assumed that the volume inside the enclosure consists of only the film base, with the chemical species of interest distributed initially uniformly throughout. For the practical scenario we considered, no mass transport is permitted across the boundaries of the enclosed volume. Therefore, given an initially uniform field of chemical species, the field will remain uniform and the concentrations depend only on time as the independent variable.

Because the system is closed, any volatile compounds present in the system (water and acetic acid) are retained completely in the film base. Assuming that deacetylation is the only reaction taking place, then the concentrations of acetyl, water and acetic acid are related by the following balance equations, which are based on the reaction in Eq. 1: 


$$
\begin{aligned}
& {[R O A c](t)=[R O A c]_{0}-\left([H O A c](t)-[H O A c]_{0}\right)} \\
& {\left[\mathrm{H}_{2} \mathrm{O}\right](t)=\left[\mathrm{H}_{2} \mathrm{O}\right]_{0}-\left([\mathrm{HOAc}](t)-[\mathrm{HOAc}]_{0}\right)}
\end{aligned}
$$

where the terms in brackets are the concentrations of the chemical species in the film base $\left(\mathrm{mol} \mathrm{m}^{-3}\right)$, $t$ is time (s) and the subscript 0 denotes the initial concentration of the component at time $t=0$.

In order to solve the equations, we require $[H O A c](t)$, the acetic acid concentration as a function of time. We assumed that the acid-catalysed mechanism dominated the deacetylation reaction kinetics in this system, compared with neutral or base-catalysed mechanisms. This requires $[\mathrm{HOAC}]_{0}>0$. The free acidity in fresh CTA film is about 0.04, meeting the minimum requirement (22). Defining the control volume as the enclosed volume of film base, the mass balance on acetic acid is:

$$
\frac{d[H O A c]}{d t}=k[R O A c]\left[\mathrm{H}_{2} \mathrm{O}\right][\mathrm{HOAc}]
$$

where $k$ is the rate constant $\left(\mathrm{mol}^{-2} \mathrm{~m}^{6} \mathrm{~s}^{-1}\right)$.

The temperature dependence of $k$ is given according to the Arrhenius equation:

$$
k=A e^{-E_{a} / R T}
$$

where $A$ is the pre-exponent factor $\left(\mathrm{mol}^{-2} \mathrm{~m}^{6} \mathrm{~s}^{-1}\right), E_{a}$ is the activation energy $\left(\mathrm{kJ} \mathrm{mol}^{-1}\right), R$ is the ideal gas constant $\left(\mathrm{kJ} \mathrm{mol}^{-1} \mathrm{~K}^{-1}\right)$ and $T$ is the temperature $(\mathrm{K})$.

The kinetic model is characterised by the following set of assumptions:

1. First order in acetyl concentration: Deacetylation of CTA in solution shows a first-order dependence on degree of substitution (35). It is known that the reactivity of acetyl groups varies with the carbon position, and this appears to affect the order in which they react, although this depends on the particular reaction conditions (36-42). In industrial processes, CTA is partially hydrolysed to yield different grades of CA, which may contain different distributions of acetylated carbons (27). Our model considered the reacting acetyl groups as equivalent, independent of acetyl position and degree of substitution. This approach has been successfully applied in other models of this reaction $(32,43)$. Mathematically, this approach is suitable if either reactions of different acetyls have identical rates, or one reaction is significantly faster than other reactions. In the latter case, the validity range of the model is limited by the concentration of the fast-reacting acetyl in the initially dominating reaction, because as the concentration fast-reacting acetyl becomes exhausted, this reaction will cease to dominate the overall deacetylation rate.

2. First order in water concentration: This was based on consideration of the reaction stoichiometry. This dependency marks our kinetic expression as different from that for a typical aqueous ester hydrolysis, which does not depend on water concentration. However, given the relative scarcity of water in CA film compared to an aqueous reaction phase, this difference in dependency makes sense.

3. First order dependence on acetic acid concentration: The reaction rate depends on [HOAC] as the acid catalyses it. In an aqueous solution, the rate of the acid-catalysed reaction ought to depend on $\left[\mathrm{H}^{+}\right](43)$. As we will be investigating the reaction in solid film base, not solution, this quantity is difficult to measure or even define. Conveniently, free acidity is considered a reliable measurement of acetic acid content in CTA film base, rather than the concentration of hydrogen ions (31). A first-order dependence on the concentration of acidic hydrolysis products, not on $\left[\mathrm{H}^{+}\right]$, was proposed by Pitt et al. while working on poly ( $\epsilon$-caprolactone) (44). This type of model is considered generally applicable in the field of polymer degradation kinetics $(45,46)$. An analysis of free acidity changes in CTA films during accelerated ageing 
observed a first-order dependence on free acidity, so we used this result (32). The mechanism of acid catalysis in this system is difficult to speculate on. In the absence of a solvent, the wellestablished mechanism of acid-catalysed ester hydrolysis via protonation of the carbonyl group may not be relevant. There is currently a lack of literature on the mechanism of acid catalysis in the case of a solid-phase ester and a vapour-phase acid and without this theoretical base, it is beyond the scope of this paper to identify a reaction mechanism.

To simplify the notation, we define the following constants:

$$
\begin{aligned}
& a \equiv[\text { ROAc }]_{0}+[\mathrm{HOAC}]_{0} \\
& b \equiv\left[\mathrm{H}_{2} \mathrm{O}\right]_{0}+[\mathrm{HOAC}]_{0}
\end{aligned}
$$

Hence Eq. 2 and 3 become:

$$
\begin{aligned}
& {[R O A c](t)=a-[H O A c](t)} \\
& {\left[\mathrm{H}_{2} \mathrm{O}\right](t)=b-[\mathrm{HOAc}](t)}
\end{aligned}
$$

The expressions for $[\mathrm{ROAC}]$ and $\left[\mathrm{H}_{2} \mathrm{O}\right]$ in Eqs. 8 and 9 are substituted into Eq. 4 to obtain a differential equation with one time-dependent variable, $[\mathrm{HOAc}]$ :

$$
\frac{d[H O A c]}{d t}=k(a-[H O A c])(b-[H O A c])[H O A c]
$$

This equation describes how the concentration of acetic acid varies in time. Assuming that free acidity provides a direct means to measure acetic acid concentration, this formulation has the advantage that most of the published literature which employed the relevant experimental procedures (the bag method and the can method) measured the extent of deacetylation by measuring free acidity over time.

\section{Results and discussion}

\subsection{Parameter estimation}

The kinetic parameters $A$ and $E_{a}$ were estimated by fitting data from artificial aging experiments carried out by other research groups to our model. In these studies, the free acidity of CTA film was measured to assess the impact of temperature and $\mathrm{RH}$ on the rate at which the vinegar syndrome progresses (17). Fresh CTA film was moisture-conditioned at $21{ }^{\circ} \mathrm{C}$ and $50 \% \mathrm{RH}$. The film was then incubated using the bag method.

Data from film base pre-conditioned at $50 \% \mathrm{RH}$ was used to estimate the kinetic parameters, as it was the only RH for which the data were available over a wide range of temperatures. Experimental results had to be estimated from graphical observation. The data we used are presented in Table 1. Measurements over 5.2 acidity were excluded from the data we analysed because the authors of the study believed that, at higher acidity, some of the acetic acid may have been lost between removing the film from the bag and making the measurements (17). The maximum temperature used, $100{ }^{\circ} \mathrm{C}$, is below the glass transition temperature of CTA film, observed at around approximately $120^{\circ} \mathrm{C}(47)$. 
Table 1: Experimental data used for estimating kinetic parameters (17).

\begin{tabular}{llllllll}
\hline & $\mathbf{7 0 ^ { \circ } \mathbf { C }}$ & & $\mathbf{8 0}^{\circ} \mathbf{C}$ & & $\mathbf{9 0}^{\circ} \mathbf{C}$ & & $\mathbf{1 0 0}^{\circ} \mathbf{C}$ \\
\hline $\begin{array}{l}\text { Time } \\
\text { (days) }\end{array}$ & $\begin{array}{l}\text { Free acidity } \\
(\mathrm{mL})\end{array}$ & $\begin{array}{l}\text { Time } \\
\text { (days) }\end{array}$ & $\begin{array}{l}\text { Free acidity } \\
(\mathrm{mL})\end{array}$ & $\begin{array}{l}\text { Time } \\
\text { (days) }\end{array}$ & $\begin{array}{l}\text { Free acidity } \\
(\mathrm{mL})\end{array}$ & $\begin{array}{l}\text { Time } \\
\text { (days) }\end{array}$ & $\begin{array}{l}\text { Free acidity } \\
(\mathrm{mL})\end{array}$ \\
0 & 0.04 & 0 & 0.04 & 0 & 0.04 & 0 & 0.04 \\
30 & 0.1 & 25 & 0.25 & 5 & 0.1 & 2 & 0.1 \\
60 & 0.25 & 50 & 3.4 & 10 & 0.2 & 4 & 0.2 \\
75 & 0.6 & 60 & 5.2 & 20 & 3.2 & 8 & 0.8 \\
90 & 1.3 & & & & & 15 & 1.5 \\
114 & 4.6 & & & & & 20 & 4.7 \\
\hline
\end{tabular}

We estimated $k$ at different temperatures by fitting our model to this data. To do this, we rearranged Eq. 10 to integrate it:

$$
\int_{[H O A c]_{0}}^{[H O A c]} \frac{1}{(a-x)(b-x) x} d x=\int_{0}^{t} k d \tau
$$

where $x$ and $\tau$ are dummy integration variables. We solved Eq. 11 analytically (see Appendix 1), obtaining an implicit solution:

$$
\begin{aligned}
& \alpha \ln \left(\frac{[H O A c]-a}{[H O A c]_{0}-a}\right)+\beta \ln \left(\frac{[H O A c]-b}{[H O A c]_{0}-b}\right)+\gamma \ln \left(\frac{[H O A c]}{[H O A c]_{0}}\right)=k t \\
& \alpha \equiv \frac{1}{a(b-a)} \\
& \beta \equiv \frac{1}{b(b-a)} \\
& \gamma \equiv \frac{1}{a b}
\end{aligned}
$$

\begin{tabular}{|c|c|c|}
\hline Quantity & Value $\left(\mathrm{mol} \mathrm{m}^{-3}\right)$ & Description \\
\hline$[\mathrm{ROAC}]_{0}$ & 13403.6 & Based on density of cellulose triacetate (28). \\
\hline$\left[\mathrm{H}_{2} \mathrm{O}\right]_{0}$ & 2137.2 & $\begin{array}{l}\text { Based on the moisture isotherm for fresh CTA film base at } 20^{\circ} \mathrm{C} \text {, as } \\
\text { this was the nearest temperature to } 21^{\circ} \mathrm{C} \text { for which the data was } \\
\text { available (48). }\end{array}$ \\
\hline$[\mathrm{HOAC}]_{0}$ & 5.2 & $\begin{array}{l}\text { Calculated by converting the measured free acidity at } t=0 \text { (see Table } \\
1 \text {, and Appendix 2) to acetic acid concentration. }\end{array}$ \\
\hline
\end{tabular}

The free acidity data in Table 1 were processed according to Eq. 12, using the initial conditions in Table 2. The procedure for converting between free acidity into acetic acid concentration is explained in Appendix 2.

Table 2: Initial conditions used to process data in Table 1.

By plotting the left-hand side of Eq. 12 against time (Figure 2), it is possible to visualise how the rate constant $k$ was found from the gradient of the best-fit line at each temperature. 


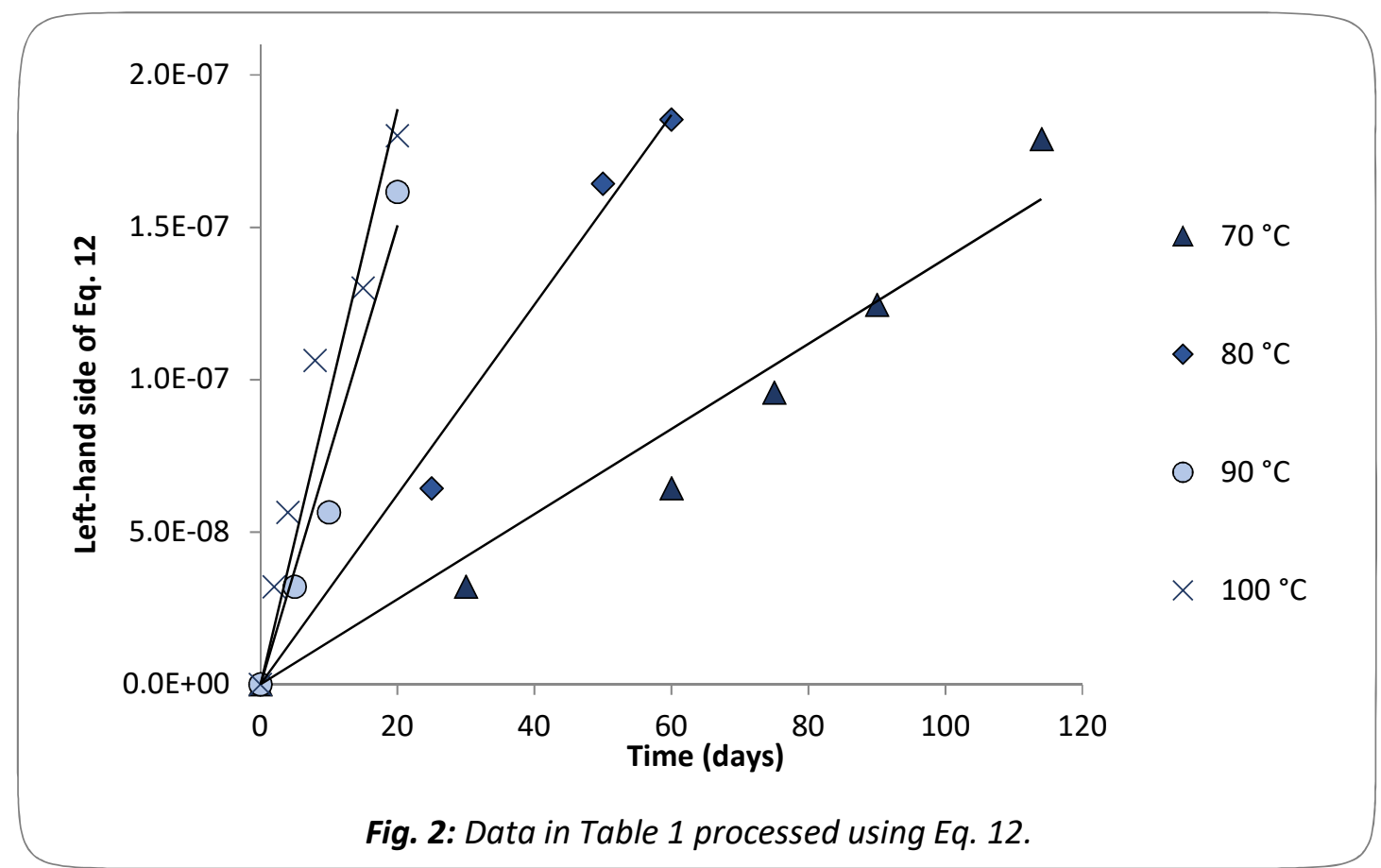

The rate constant $k$ was estimated at each temperature by calculating the slope of the best-fit line, where the $y$-intercept was set to zero. This was done using linear least squares regression in Microsoft Excel ${ }^{\mathrm{TM}}$. The results are reported in Table 3. The errors in $k$ refer to the standard error in the gradient. The high $r^{2}$ values suggest that Eq. 12 is a good fit for the data and hence supports the validity of the kinetic model for this reaction system.

Table 3: Values of $k$ estimated for each temperature.

\begin{tabular}{lll}
\hline Temperature $\left({ }^{\circ} \mathbf{C}\right)$ & $\boldsymbol{k} \times \mathbf{1 0}^{-\mathbf{1 4}}\left(\mathbf{m o l}^{-\mathbf{2}} \mathbf{~}^{\mathbf{6}} \mathbf{s}^{-\mathbf{1}}\right)$ & $\boldsymbol{r}^{\mathbf{2}}$ \\
\hline $\mathbf{7 0}$ & $1.62 \pm 0.09$ & 0.985 \\
$\mathbf{8 0}$ & $3.6 \pm 0.1$ & 0.996 \\
$\mathbf{9 0}$ & $8.7 \pm 0.7$ & 0.983 \\
$\mathbf{1 0 0}$ & $10.9 \pm 0.8$ & 0.974 \\
\hline
\end{tabular}

The data in Table 3 were linearised by rearranging Eq. 5 to the following form:

$$
\ln k=\ln A-\left(\frac{E_{a}}{R}\right)\left(\frac{1}{T}\right)
$$

Plotting $\ln k$ against $1 / T$ (Figure 3 ) shows how $\ln A$ was found from the $y$-intercept of the best-fit line, and $E_{a} / R$ from the gradient. This was done using linear least squares regression in Microsoft Excel ${ }^{\mathrm{TM}}$. The results are reported in Table 4.

Table 4: Estimated kinetic parameters.

\begin{tabular}{ll}
\hline Quantity & Value \\
\hline $\ln \boldsymbol{A}$ & $-6.9 \pm 3.4$ \\
$\boldsymbol{A}$ & $0.00103_{-0.000996}^{+0.030159 \mathrm{~mol}^{-2} \mathrm{~m}^{6} \mathrm{~s}^{-1}}$ \\
$\frac{\boldsymbol{E}_{\boldsymbol{a}}}{\boldsymbol{R}}$ & $8508 \pm 1220 \mathrm{~K}$ \\
$\boldsymbol{E}_{\boldsymbol{a}}$ & $70.734 \pm 10.141 \mathrm{~kJ} \mathrm{~mol}^{-1}$ \\
$\boldsymbol{r}^{2}$ & 0.961 \\
\hline
\end{tabular}




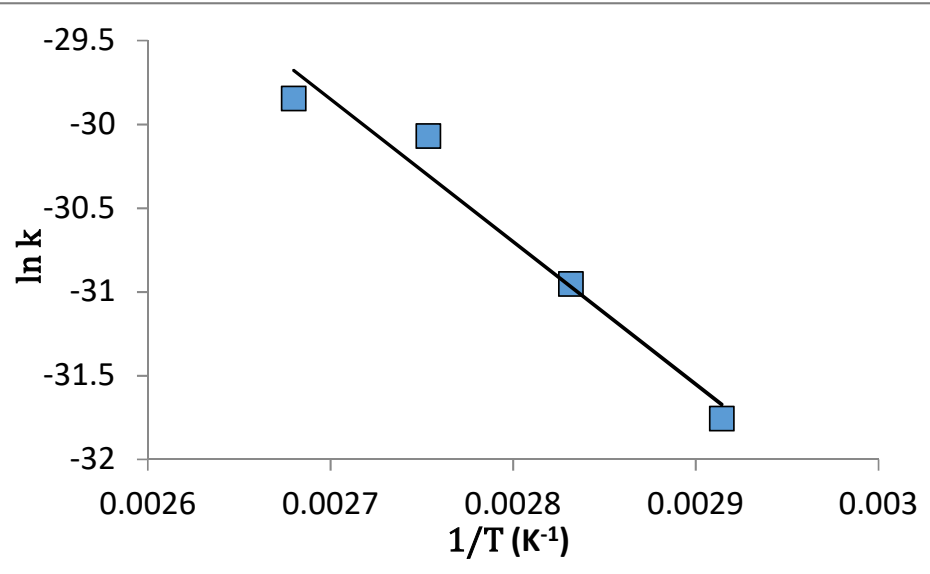

Fig. 3: Estimated rate constants at different (reciprocal) temperatures.

The relatively large error in $\ln A$ is due in part to the small number of data points used in the fitting. The precision could be improved by taking measurements at more temperatures. As these errors are magnified exponentially when calculating $A$, this causes the asymmetry in the final reported standard errors.

Other studies have estimated the activation energy of the deacetylation of cellulose acetate, under various conditions and with different models. These are summarised in Table 5.

Table 5: Deacetylation activation energies reported in the literature.

\begin{tabular}{|c|c|c|}
\hline$E_{a}\left(\mathrm{~kJ} \mathrm{~mol}^{-1}\right)$ & Reaction system & Model description \\
\hline 92.048 & CTA film at $20 \% \mathrm{RH}$. & \multirow{4}{*}{$\begin{array}{l}\text { Zero-order kinetics. Based on time taken to } \\
\text { reach free acidity of } 0.5 \text { (33). }\end{array}$} \\
\hline 87.864 & CTA film at $50 \%$ RH. & \\
\hline 87.864 & CTA film at $60 \% \mathrm{RH}$. & \\
\hline 83.68 & CTA film at $80 \%$ RH. & \\
\hline 68.6 & $\begin{array}{l}\text { Cellulose acetate reverse osmosis (RO) } \\
\text { membranes in aqueous solution (acid- } \\
\text { catalysed). }\end{array}$ & \multirow{3}{*}{$\begin{array}{l}\text { Models acid-catalysed, base-catalysed and } \\
\text { neutral reactions separately, with a first- } \\
\text { order dependence on degree of } \\
\text { substitution. For the acid- and base- } \\
\text { catalysed reactions, there is additionally a } \\
\text { first-order dependence on the activity of } \mathrm{H}^{+} \\
\text {and } \mathrm{OH}^{-} \text {in solution, respectively (43). }\end{array}$} \\
\hline 34.0 & $\begin{array}{l}\text { Cellulose acetate RO membranes in } \\
\text { aqueous solution (base-catalysed). }\end{array}$ & \\
\hline 48.1 & $\begin{array}{l}\text { Cellulose acetate RO membranes in } \\
\text { aqueous solution (neutral). }\end{array}$ & \\
\hline 59.8 & $\begin{array}{l}\text { Uncatalysed C6 deacetylation, cellulose } \\
\text { acetate dissolved in aqueous solution. }\end{array}$ & \multirow{4}{*}{$\begin{array}{l}\text { The original study modelled both the } \\
\text { forward and backward reactions, for the } \\
\text { primary and secondary acetyls ( } 36) \text {. We } \\
\text { report the results of a subsequent analysis } \\
\text { which calculated the activation energy of } \\
\text { the reaction listed (49). }\end{array}$} \\
\hline 67.4 & $\begin{array}{l}\text { Acid-catalysed C6 deacetylation, cellulose } \\
\text { acetate dissolved in aqueous solution with } \\
\text { sulphuric acid. }\end{array}$ & \\
\hline 86.2 & $\begin{array}{l}\text { Uncatalysed } \mathrm{C} 2 / \mathrm{C} 3 \text { deacetylation, cellulose } \\
\text { acetate dissolved in aqueous solution. }\end{array}$ & \\
\hline 35.6 & $\begin{array}{l}\text { Acid-catalysed C2/C3 deacetylation, } \\
\text { cellulose acetate dissolved in aqueous } \\
\text { solution with sulphuric acid. }\end{array}$ & \\
\hline
\end{tabular}

While it is impossible to directly compare the activation energy we estimated with other published values due to differences in the experimental conditions and the models, these support that our estimate is within the range reasonably expected for the reaction. 


\subsection{Model validation}

Model accuracy was evaluated by comparing the model predictions to experimental data published by other researchers for the free acidity change in $35 \mathrm{~mm}$ CTA film incubated using the can method, under different conditions of temperature and $\mathrm{RH}$. The conditions describing each experiment are summarised in Table 6.

Table 6: Experimental conditions for each validation case (34).

\begin{tabular}{lrrr}
\hline Case & Temperature $\left({ }^{\circ} \mathbf{C}\right)$ & RH (\%) & \multicolumn{2}{c}{$\begin{array}{l}\text { Initial free acidity (ml 0.1 M } \\
\text { NaOH /g CTA film base) }\end{array}$} \\
\hline A & & 50 & 0.4 \\
B & 35 & 35 & 0.46 \\
C & 35 & 20 & 0.4 \\
D & 35 & 50 & 0.4 \\
E & 21 & 35 & 0.4 \\
F & 21 & 20 & 0.4 \\
G & 21 & 50 & 0.58 \\
\hline
\end{tabular}

We used our model to predict free acidity (acetic acid concentration) as a function of time for each case. The rate constant $k$ was calculated from the temperature using Eq. 5 and the estimated parameters $A$ and $E_{a}$. The initial conditions $[\mathrm{ROAc}]_{0},\left[\mathrm{H}_{2} \mathrm{O}\right]_{0}$ and $[\mathrm{HOAc}]_{0}$ were required to integrate Eq. 10.

According to the authors of the published data, the samples were prepared by moisture-conditioning fresh CTA film at $21{ }^{\circ} \mathrm{C}$ and $50 \% \mathrm{RH}$. They were then incubated using the bag method at $90{ }^{\circ} \mathrm{C}$ until the samples reached a free acidity of approximately 0.4 (the precise value is indicated as the initial free acidity in Table 6). In cases $\mathrm{A}-\mathrm{F}$, the samples were then moisture-conditioned again at $21^{\circ} \mathrm{C}$ and their respective $\mathrm{RH}$, before being incubated using the can method at either $21^{\circ} \mathrm{C}$ or $35^{\circ} \mathrm{C}$. In case $\mathrm{G}$, the sample was not re-conditioned before the second incubation as it was found that the difference in moisture content before and after the first incubation was insignificant compared with the total water content inside the roll (34).

The initial acetic acid concentration was determined from the measured free acidity at $t=0$. The initial water concentration is based on the moisture isotherm for fresh CTA film at $20{ }^{\circ} \mathrm{C}$, as this was the nearest temperature to $21{ }^{\circ} \mathrm{C}$ for which the data was available (48). The reported moisture content at $21 \% \mathrm{RH}$ was used for the moisture content at $20 \% \mathrm{RH}$ as this was the lowest value reported. The initial acetyl concentration was calculated from the following mass balance, where $13403.6 \mathrm{~mol} \mathrm{~m}^{-3}$ is the concentration of acetyl in fresh CTA, and $5.2 \mathrm{~mol} \mathrm{~m}^{-3}$ is the concentration of acetic acid in fresh CTA film (22):

$$
[R O A c]_{0}=13403.6-\left([H O A c]_{0}-5.2\right)
$$

The model inputs for each case are summarised in Table 7.

Table 7: Initial conditions used to simulate each validation case.

\begin{tabular}{lllll}
\hline Case & Temperature $\left(^{\circ} \mathrm{C}\right)$ & {$[\mathbf{H O A C}]_{\mathbf{0}}\left(\mathbf{m o l ~ m}^{-\mathbf{3}}\right)$} & {$\left[\mathbf{H}_{\mathbf{2}} \mathbf{O}\right]_{\mathbf{0}}\left(\mathbf{m o l ~ m}^{-\mathbf{3}}\right)$} & {$[R O A c]_{\mathbf{0}}\left(\mathbf{m o l ~ m}^{-\mathbf{3}}\right)$} \\
\hline A & 35 & 52 & 2137.2 & 13356.8 \\
B & 35 & 59.8 & 1605.2 & 13349.0 \\
C & 35 & 52 & 1010.0 & 13356.8 \\
D & 21 & 52 & 2137.2 & 13356.8 \\
E & 21 & 52 & 1605.2 & 13356.8 \\
F & 21 & 52 & 1010.0 & 13356.8 \\
G & 21 & 75 & 2137.2 & 13333.8 \\
\hline
\end{tabular}

Using these inputs for each case, numerical integration of Eq. 10 was carried out in MATLAB ${ }^{\circledR}$ R2018a using the solver ode1 $5 \mathrm{~s}$. The predicted free acidity values are shown with the experimental measurements of free 
acidity in Figures 4 and 5. For cases D-G, the reported experimental values are the mean of three measurements taken at three different locations in the film roll, with the error bars indicating the minimum and maximum values. In cases $A-C$, only the mean values were reported in the original report. In case $G$, the authors measured after 15 months a sharp reduction in the free acidity, but they did not explain the reason for this. This surprising behaviour cannot be predicted with our model but as a decrease in free acidity after exposure to high humidity is unlikely and it may be due to experimental error, we have excluded these data points from the analysis.
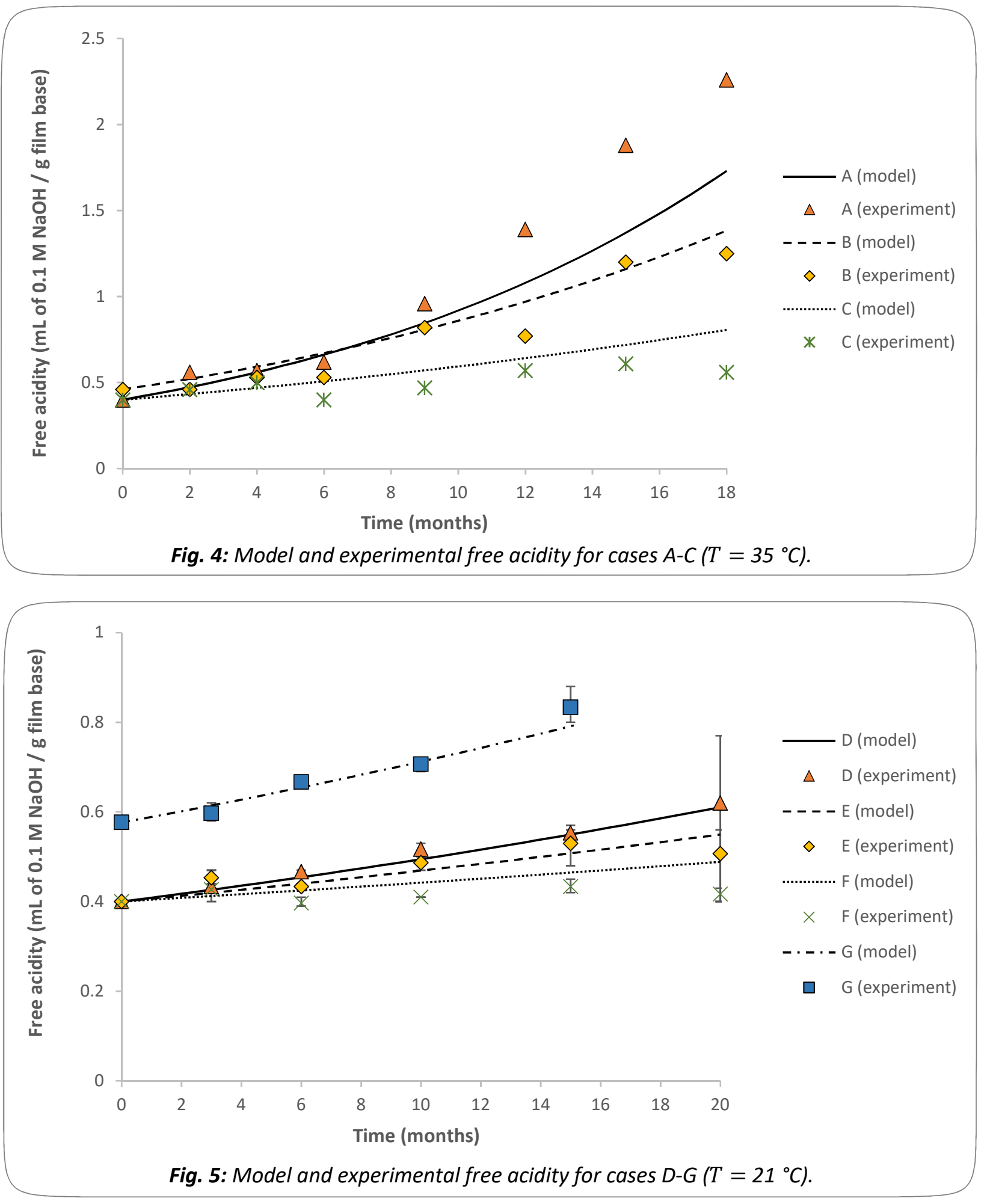
The accuracy of the model predictions was evaluated using the normalised-root-mean-square-error (NRMSE) as the cost function. In this statistical test, the worst score is $-\infty$, a perfect score is 1 , and a score of 0 indicates the model is no better than a horizontal straight line (through the mean value) at fitting the data (50). The results are reported in Table 8.

Table 8: Accuracy of the model predictions against experimental data.

\begin{tabular}{ll}
\hline Case & Accuracy score \\
\hline A & 0.4551 \\
B & 0.7105 \\
C & -0.3202 \\
D & 0.8450 \\
E & 0.4278 \\
F & -1.7857 \\
G & 0.7684 \\
\hline
\end{tabular}

In summary, the model performed best at RH of 50 and $35 \%$ (cases A, B, D, E and G), and poorly at 20\% RH (cases $\mathrm{C}$ and $\mathrm{F}$ ). The best fit was found with $21^{\circ} \mathrm{C}$ and $50 \% \mathrm{RH}$ (experiment $\mathrm{D}$ ).

We investigated whether an error in $\left[\mathrm{H}_{2} \mathrm{O}\right]_{0}$ could explain the poor accuracy of the model at $20 \% \mathrm{RH}$. For cases $\mathrm{C}$ and $\mathrm{F}$, the model was run with varying $\left[\mathrm{H}_{2} \mathrm{O}\right]_{0}$ to obtain the value that maximised the accuracy score. For case $\mathrm{C}$, the optimal fit was obtained using $\left[\mathrm{H}_{2} \mathrm{O}\right]_{0}=636 \mathrm{~mol} \mathrm{~m}^{-3}$ which resulted in an accuracy score of 0.4042 . For case $\mathrm{G}$, the optimal fit was obtained using $\left[\mathrm{H}_{2} \mathrm{O}\right]_{0}=317 \mathrm{~mol} \mathrm{~m}^{-3}$ which resulted in an accuracy score of 0.0591 . Given that neither of these values for $\left[\mathrm{H}_{2} \mathrm{O}\right]_{0}$ are particularly close to the reference we used $\left(1010 \mathrm{~mol} \mathrm{~m}^{-3}\right)$, and that the values are not close to each other, we concluded that an error in $\left[\mathrm{H}_{2} \mathrm{O}\right]_{0}$ does not explain the poor accuracy of the model at $20 \% \mathrm{RH}$.

One theory is that different mechanisms are responsible for the observed behaviour at high (50 and 35\%) RH and low (20\%) RH. We explain this by way of an analogy which compares our model to a model of hydrolysis in aqueous solution.

In our model, the first-order dependence of the reaction rate on $[H O A c]$ is based on empirical observation, where the experimental conditions consisted of solid CTA films prepared by equilibrating with a gas ( $50 \% \mathrm{RH}$ ) before being placed in a vacuum-sealed bag (17). In a mechanistic model of acid-catalysed hydrolysis in aqueous solution, the rate dependence on $[\mathrm{HOAC}]$ is expected to be of order $1 / 2$, since the acid-catalysed mechanism depends on $\left[\mathrm{H}^{+}\right]$:

$$
\left[H^{+}\right]=\sqrt{K_{a}[H O A c]}
$$

where $K_{a}$ is the acid dissociation constant $\left(\mathrm{mol} \mathrm{m}^{-3}\right.$ ) of acetic acid. We have not proposed a mechanistic model for acid-catalysed hydrolysis of solid films, but the difference in the dependence on [HOAc] between our model and the mechanistic model of acid-catalysed hydrolysis in solution acknowledges that the ratedetermining mechanisms in the two conditions differ as well. Hence, it is not an unlikely possibility that yet another set of mechanisms determines the rate of generation of acetic acid at low RH conditions, compared to high $\mathrm{RH}$ conditions.

As an example to illustrate this point: In solution $\left[\mathrm{H}_{2} \mathrm{O}\right]$ is essentially constant, therefore it does not feature as a variable in the rate expression for this system, whereas in our model system, $\left[\mathrm{H}_{2} \mathrm{O}\right]$ is rate-limiting. By analogy, it is possible that some unknown variable which is rate-limiting at low $\mathrm{RH}$ is not rate-limiting at high $\mathrm{RH}$, therefore our exclusion of the unknown variable(s) from the model only has a noticeable effect on the accuracy of the model at low RH (51). 


\subsection{Model predictions vs. guidelines}

Guidelines for CTA film conservation provide estimates for film permanence in terms of the number of years for fresh film to reach a free acidity of 0.5 , when stored under specified temperature and $\mathrm{RH}(21)$. These are intended as "worst-case scenario" estimates, where it is assumed that the maximum amount of acetic acid is retained in the film base, as these were the conditions from which the guidelines extrapolated. However, the guidelines assumed a constant rate of reaction during the induction phase, and did not take into account catalysis by acetic acid. The assumption of maximum acid retention is necessary for the guidelines because it permits the free acidity to be used as a direct measure of the extent of the reaction, not because the presence of the acid is directly modelled as having an effect on the reaction rate. The data we used for the parameter estimation are from the same experiments on which the guidelines are based, therefore any differences between our predictions and the guidelines are due to the theory that was applied in each. The values of the film permanence predicted by our model and by the guidelines as a function of temperature are shown in Figure 6 , with initial moisture-conditioning at 20,40 and $60 \% \mathrm{RH}$. No equation is provided by the guidelines so we present their tabulated values.

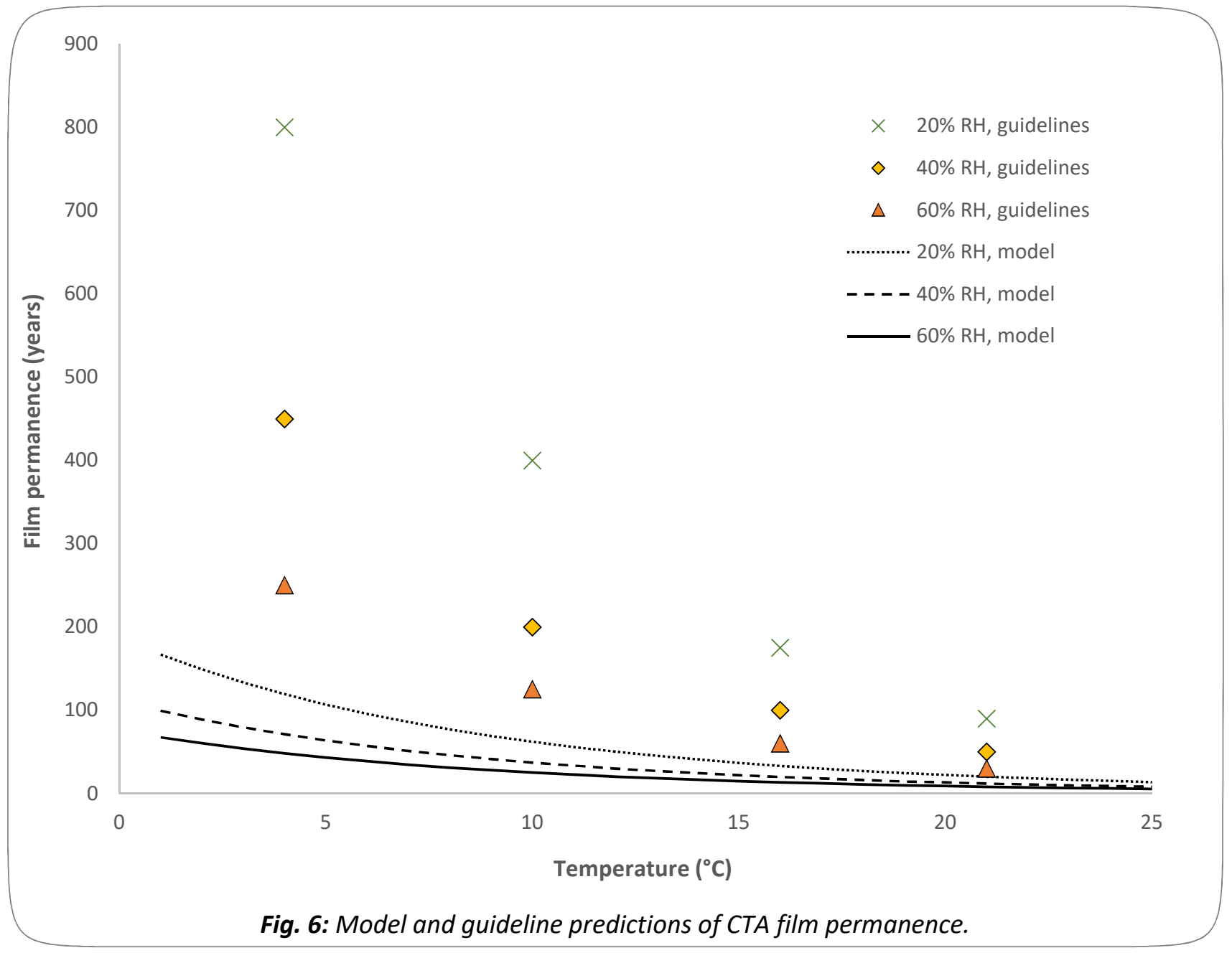

The model predicts that the film permanence is less than what is stated by the guidelines at every RH and temperature, with the magnitude of the gap increasing at lower temperatures. For example, at $40 \% \mathrm{RH}$ and $21{ }^{\circ} \mathrm{C}$ the guidelines say the film permanence is 50 years and the model predicts 12.1 years ( 37.9 years difference, or $75.8 \%$ less), but at $40 \% \mathrm{RH}$ and $4{ }^{\circ} \mathrm{C}$, the guidelines say the film permanence is 450 years and the model predicts 71.2 years ( 378.8 years difference, or $84.2 \%$ less).

Most likely, the reason that the model and the guidelines do not agree is that our model accounts for the effect of autocatalysis, while the guidelines do not. Other possible differences between the model and the guidelines, for example in the assumptions about moisture content, cannot explain the discrepancy between 
the two sets of predictions. Because the guidelines are based on the extrapolation of data of film conditioned at $21{ }^{\circ} \mathrm{C}$ and the specified $\mathrm{RH}$ prior to sealing in an air-tight enclosure, we assumed that the initial moisture content in our model corresponds to that at $21^{\circ} \mathrm{C}$, rather than the equilibrium moisture content at the storage temperature (21). This is actually the "best-case scenario" with respect to moisture as moisture content increases with lower temperature (48). Moreover, if the moisture content was maintained at constant levels while somehow ensuring maximum acid-trapping, this would result in higher moisture content throughout, as it would counter the depletion of water that otherwise occurs in the closed system. Either of these assumptions-moisture-conditioning at the storage temperature, or constant moisture levels-increases the reaction rate, reducing the predicted film permanence further.

\subsection{Consequences for film conservation}

Several factors are believed to influence the rate of CTA film degradation (Table 9), pertaining either to its care (exogenous factors) or intrinsic characteristics (endogenous factors). It is not well-established how much these factors contribute to degradation relative to temperature and $\mathrm{RH}$, nor are the complex interactions between different factors well-characterised.

Table 9: Exogenous and endogenous factors that influence CTA film degradation.

\begin{tabular}{ll}
\hline Exogenous factors & Increasing the temperature increases the rate constant $k$. \\
\hline $\begin{array}{l}\text { Temperature } \\
\text { Relative humidity }\end{array}$ & $\begin{array}{l}\text { Water is a reactant in the hydrolysis of CTA. } \\
\text { acetic acid from escaping from the film, increasing the potential } \\
\text { for autocatalysis (19,52); ventilated containers facilitate the } \\
\text { escape of acetic acid (53). }\end{array}$ \\
\hline Iron cans accelerate the degradation rate compared with other \\
materials, for example glass (54).
\end{tabular}

It is widely recommended that cold storage is the best option to prolong the life of film, which implies that temperature has the greatest impact relative to other (exogenous) factors, or that it is the most cost-effective $(18,55,56)$. This may be true, and our model does not dispute this necessarily. Controlling the macroenvironment is often the cheapest option, next to doing nothing $(57,58)$. In many cases, this will make it the only option that conservators can realistically pursue. However, our model does suggest that the impact of cold storage (and low RH) on prolonging the life of film is less than what is set out by the guidelines. This should be of critical interest to CTA film archivists who are using these guidelines to inform the preservation strategy for their collections.

Bearing in mind the model errors and the variability in real collections compared with the idealised model system, the magnitudes of the predicted film permanences are notable, compared to the guidelines, for three 
reasons. First, cellulose acetate (presumably) never existed until less than 200 years ago. It is therefore impossible to validate the accuracy of any predictions which exceed this timeframe. The model predictions are within a timeframe that make it possible to test against real collections. Second, based on the model, there are archives which are already or very soon past the point of vinegar syndrome, much earlier than expected even with cold storage. This risk should be addressed immediately. Third, the timescales of the model predictions are within the scale of the human lifetime, or the age of an institutional archive, or the duration of employment for a film conservator. This compels the responsibility of present-day custodians of film collections to initiate alternative long-term strategies, for example digitisation, as it may not be an option to leave this to their successors.

\section{Conclusions}

We have proposed a mathematical model which accounts for the autocatalytic effect of acetic acid on the vinegar syndrome. This model is based on an understanding of the reaction chemistry which has been established by other researchers in the field. The good agreement between the predictions and previously published experimental data lend convincing support to the accuracy of the model. The model predicts that the free acidity will increase at a significantly faster rate than what is suggested by the guidelines, which do not account for the autocatalytic effect, despite representing the worst-case scenario with maximum acidtrapping.

Given the prevalence of cold storage as a long-term strategy for extending the life of CTA film, these results have urgent consequences for film conservation. Other long-term strategies, such as duplication to another medium, may be necessary much sooner than had been appreciated.

\section{Disclosure statement}

No potential conflict of interest was reported by the authors.

\section{Funding}

This project was supported by the European Research Council under the European Union's Horizon 2020 research and innovation programme (grant agreement No 716390); and the Engineering and Physical Sciences Research Council (grant number EP/L016036/1).

\section{Appendix A: Derivation of analytical solution to Eq. 11}

The equation to be integrated is:

$$
\int_{[H O A c]_{0}}^{[H O A c]} \frac{1}{(a-x)(b-x) x} d x=\int_{0}^{t} k d \tau
$$

The term to be integrated on the left-hand side can be simplified by separating the factors in the denominator, introducing $\alpha, \beta$ and $\gamma$ as constants in the numerators.

$$
\begin{aligned}
& \frac{1}{(a-x)(b-x) x} \equiv \frac{\alpha}{x-a}+\frac{\beta}{x-b}+\frac{\gamma}{x} \\
& \alpha\left(x^{2}-b x\right)+\beta\left(x^{2}-a x\right)+\gamma\left(x^{2}-(a+b) x+a b\right)=1
\end{aligned}
$$

Eq. A. 3 must be true for all values of $0>x>a, b$. Therefore, we can write the following balance for terms that are multiples of $x^{2}$ :

$$
\alpha+\beta+\gamma=0
$$


For terms that are multiples of $x$ (but not $x^{2}$ ):

$$
-\alpha b-\beta a-\gamma(a+b)=0
$$

For terms that are not multiples of $x$ :

$$
\gamma a b=1
$$

Eq. A.4-A.6 define a system of three equations for three unknowns $\alpha, \beta$ and $\gamma$. The solution to this system is:

$$
\begin{aligned}
& \alpha=\frac{1}{a(b-a)} \\
& \beta=\frac{1}{b(b-a)} \\
& \gamma=\frac{1}{a b}
\end{aligned}
$$

With these solutions for the constants in Eq. A.2, we make a substitution in Eq. A.1 to solve the integration problem:

$$
\begin{aligned}
& \int_{[H O A c]_{0}}^{[H O A c]}\left(\frac{\alpha}{x-a}+\frac{\beta}{x-b}+\frac{\gamma}{x}\right) d x=\int_{0}^{t} k d \tau \\
& {[\alpha \ln (x-a)+\beta \ln (x-b)+\gamma \ln x]_{[H O A C]_{0}}^{[H O A c]}=k t} \\
& \alpha \ln \left(\frac{[H O A c]-a}{[H O A c]_{0}-a}\right)+\beta \ln \left(\frac{[H O A c]-b}{[H O A c]_{0}-b}\right)+\gamma \ln \left(\frac{[H O A c]}{[H O A c]_{0}}\right)=k t
\end{aligned}
$$

\section{Appendix B: Converting between free acidity and concentration}

Free acidity is measured by the millilitres of $0.1 \mathrm{M} \mathrm{NaOH}$ required to neutralise 1 gram of cellulose triacetate film base. Acid is extracted from $1 \mathrm{~g}$ of sample using the water-leaching method (31). This method is assumed to give an accurate measurement for how much acetic acid is present in the sample, when used with the appropriate indicator for this acid (metacresol purple) (31). A free acidity of 1 corresponds to $0.001 \mathrm{~L} \times$ $0.1 \mathrm{M} \mathrm{NaOH}=0.0001 \mathrm{~mol} \mathrm{NaOH}$, which can neutralise $0.0001 \mathrm{~mol}$ of acetic acid. The density of cellulose triacetate is $1.3 \mathrm{~g} \mathrm{~cm}^{-3}$, so the concentration of acetic acid is $0.0001 \mathrm{~mol} \mathrm{HAc} \mathrm{g}-1 \times 1.3 \times 10^{6} \mathrm{~g} \mathrm{~m}^{-3}=$ $130 \mathrm{~mol} \mathrm{~m}^{-3} \mathrm{HAc}$ (27). Hence free acidity is converted to acetic acid concentration in $\mathrm{mol} \mathrm{m}^{-3}$ by multiplying by 130 .

\section{References}

1. Fordyce CR. Improved Safety Motion Picture Film Support. J Soc Motion Pict Eng [Internet]. 1948 Oct;51(4):331-50. Available from:

http://ieeexplore.ieee.org/Ipdocs/epic03/wrapper.htm?arnumber=7250944

2. Cummings JW, Hutton AC, Silfin H. Spontaneous Ignition of Decomposing Cellulose Nitrate Film. J Soc Motion Pict Telev Eng [Internet]. 1950 Mar;54(3):268-74. Available from:

http://ieeexplore.ieee.org/lpdocs/epic03/wrapper.htm?arnumber=7251200

3. Allen NS, Edge M, Appleyard JH, Jewitt TS, Horie C V., Francis D. Degradation of historic cellulose 
triacetate cinematographic film: The vinegar syndrome. Polym Degrad Stab. 1987;19(4):379-87.

4. Horvath DG. The Acetate Negative Survey: Final Report. Holden MS, editor. Vol. 2, Topics in Photographic Preservation. Photographic Materials Group of the American Institute for Conservaton of Historic \& Artistic Works; 1988.

5. Shashoua Y. Inhibiting the inevitable; current approaches to slowing the deterioration of plastics. Macromol Symp. 2006;238:67-77.

6. Edge M, Allen NS, Williams DAR, Thompson F, Horie V. Methods for predictive stability testing of archival polymers: A preliminary assessment of cellulose triacetate based motion picture film. Polym Degrad Stab. 1992;35(2):147-55.

7. Viggiani MA. Film archival storage and preservation system. United States; US20020108876A1, 2002.

8. Holtz CF, Kopperl DF, Ram AT, Sehlin RC. Method for improving record preservability of processed photographic element and compiling device for preservation. Japan; JPH06202303A, 1992.

9. Compatible plasticizer compounds useful in polarizing plates. South Korea; KR20070053278A, 2004.

10. Li Y, Zhou Y, Cao J. Shape-restoring device and a restoring method for distored filmstrips. United States; US9250511B2, 2016.

11. Matsui $\mathrm{K}$, Ishii T, Hashimoto A. Film deterioration preventing material and acidic gas removing agent. EP3357557A1, 2016.

12. Repair methods and repaired optical image recording film of the optical image recording film. Japan; JP5176049B2, 2009.

13. Wagner GE. Method and apparatus for restoring and stabilising motion picture film. United States; US6969581B1, 2005.

14. Sawaguchi T, Yano S, Morimatsu Y, Sakaki M. Method of removing acid component in deteriorated acetate film. United States; US7144461B2, 2006.

15. Gleich A. Apparatus and a method for processing media, particularly paper, film, leather or fabric. Germany; DE102014111807A1, 2014.

16. Film deterioration prevention material. Japan; JP5991506B2, 2011.

17. Adelstein PZ, Reilly JM, Nishimura DW, Erbland CJ. Stability of cellulose ester base photographic film: part I - laboratory testing procedures. Soc Motion Pict Telev Eng J. 1992;101(5):336-46.

18. Adelstein PZ, Reilly JM, Nishimura DW, Erbland CJ. Stability of cellulose ester base photographic film: part II - practical storage considerations. Soc Motion Pict Telev Eng J. 1992;101(5):347-53.

19. Allen NS, Edge M, Appleyard JH, Jewitt TS, Horie C V., Francis D. Acid-catalysed degradation of historic cellulose triacetate, cinematographic film: Influence of various film parameters. Eur Polym J. 1988;24(8):707-12.

20. Edge M, Allen NS, Jewitt TS, Horie C V. Fundamental aspects of the degradation of cellulose triacetate base cinematograph film. Polym Degrad Stab [Internet]. 1989;25(2-4):345-62. Available from: http://dx.doi.org/10.1016/S0141-3910(89)81016-X

21. Reilly JM. IPI Storage Guide for Acetate Film. Rochester, NY: Image Permanence Institute, Rochester Institute of Technology; 1993.

22. Adelstein PZ, Reilly JM, Nishimura DW, Erbland CJ, Bigourdan J-L. Stability of cellulose ester base photographic film: part V - recent findings. Soc Motion Pict Telev Eng J. 1995;104(7):439-47. 
23. Williams RS. Care of Plastics: Malignant plastics. WAAC Newsletter [Internet]. 2002 [cited 2019 Aug 8];24(1). Available from: http://cool.conservation-us.org/waac/wn/wn24/wn24-1/wn24-102.html

24. Puls J, Wilson SA, Hölter D. Degradation of Cellulose Acetate-Based Materials: A Review. J Polym Environ. 2011;19(1):152-65.

25. Quintana R, Persenaire O, Lemmouchi Y, Sampson J, Martin S, Bonnaud L, et al. Enhancement of cellulose acetate degradation under accelerated weathering by plasticization with eco-friendly plasticizers. Polym Degrad Stab [Internet]. 2013;98(9):1556-62. Available from: http://dx.doi.org/10.1016/j.polymdegradstab.2013.06.032

26. Chanda M, Roy S. Industrial Polymers. In: Plastics Technology Handbook. 4th ed. Boca Raton, FL: CRC Press, Taylor \& Francis; 2007. p. 128-32.

27. Heinze T, Liebert T. 4. Characteristics of celllose acetates -4.2 Chemical characteristics of cellulose acetate. Macromol Symp. 2004;208:167-237.

28. Zugenmaier P. 4. Characteristics of cellulose acetates-4.1 Characterization and physical properties of cellulose acetates. Macromol Symp [Internet]. 2004 Mar;208(1):81-166. Available from: http://doi.wiley.com/10.1002/masy.200450407

29. Carollo P, Grospietro B. 5.5 Plastic materials. Macromol Symp [Internet]. 2004 Mar;208(1):335-52. Available from: http://doi.wiley.com/10.1002/masy.200450414

30. Hanson JA. Functional group chemistry. Cambridge, UK: Royal Society of Chemistry; 2001. 11 p.

31. Adelstein PZ, Reilly JM, Nishimura DW, Erbland CJ. Stability of cellulose ester base photographic film: part III - measurement of film degradation. Soc Motion Pict Telev Eng J. 1995;104(5):281-91.

32. Knight B. Lack of evidence for an autocatalytic point in the degradation of cellulose acetate. Polym Degrad Stab [Internet]. 2014;107:219-22. Available from:

http://dx.doi.org/10.1016/j.polymdegradstab.2013.12.002

33. Reilly J-M, Nishimura DW, Zinn E. New Tools for Preservation: Assessing Long-Term Environmental Effects on Library and Archives Collections. Washington, D.C.: The Commission on Preservation and Access; 1995.

34. Bigourdan J-L, Reilly JM. Environment and Enclosures in Film Preservation. 1997.

35. de Freitas RRM, Senna AM, Botaro VR. Influence of degree of substitution on thermal dynamic mechanical and physicochemical properties of cellulose acetate. Ind Crops Prod [Internet]. 2017;109(March):452-8. Available from: http://dx.doi.org/10.1016/j.indcrop.2017.08.062

36. Hiller Jr. LA. The reaction of cellulose acetate with acetic acid and water. J Polym Sci. 1953;10(4):385423.

37. Derham M, Edge M, Williams DAR, Williamson DM. The degradation of cellulose triacetate studied by nuclear resonance spectroscopy and molecular modeling. In: Allen NS, Edge M, Horie C V., editors. Polymers in Conservation. Royal Society of Chemistry; 1992. p. 125-37.

38. Kono H, Oka C, Kishimoto R, Fujita S. NMR characterization of cellulose acetate: Mole fraction of monomers in cellulose acetate determined from carbonyl carbon resonances. Carbohydr Polym [Internet]. 2017;170:23-32. Available from: http://dx.doi.org/10.1016/j.carbpol.2017.04.061

39. Samios E, Dart RK, Dawkins J V. Preparation, characterization and biodegradation studies on cellulose acetates with varying degrees of substitution. Polymer (Guildf). 1997;38(12):3045-54.

40. Goodlett VW, Dougherty JT, Patton HW. Characterization of cellulose acetates by nuclear magnetic 
resonance. J Polym Sci Part A-1 Polym Chem. 1971;9(1):155-61.

41. Zhang K, Feldner A, Fischer S. FT Raman spectroscopic investigation of cellulose acetate. Cellulose. 2011;18(4):995-1003.

42. He J, Tang Y, Wang S-Y. Alkaline treatment of diacetate fibers and subsequent cellulase degradation. J Appl Polym Sci [Internet]. 2008 Feb 15;107(4):2466-74. Available from:

http://doi.wiley.com/10.1002/app.27373

43. Vos KD, Burris FO, Riley RL. Kinetic study of the hydrolysis of cellulose acetate in the pH range of 210. J Appl Polym Sci. 1966;10(5):825-32.

44. Pitt CG, Chasalow FI, Hibionada YM, Klimas DM, Schindler A. Aliphatic polyesters. I. The degradation of poly(e-caprolactone) in vivo. J Appl Polym Sci. 1981;26(11):3779-87.

45. Laycock B, Nikolić M, Colwell JM, Gauthier E, Halley P, Bottle S, et al. Lifetime prediction of biodegradable polymers. Prog Polym Sci. 2017;71:144-89.

46. Lyu SP, Schley J, Loy B, Lind D, Hobot C, Sparer R, et al. Kinetics and time-temperature equivalence of polymer degradation. Biomacromolecules. 2007;8(7):2301-10.

47. Sata $H$, Murayama M, Shimamoto S. 5.4 Properties and applications of cellulose triacetate film. Macromol Symp [Internet]. 2004 Mar;208(1):323-34. Available from: http://doi.wiley.com/10.1002/masy.200450413

48. Adelstein PZ, Bigourdan J-L, Reilly JM. Moisture Relationships of Photographic Film. J Am Inst Conserv. 1997;36(3):193.

49. Ram AT. Archival preservation of photographic films - A perspective. Polym Degrad Stab. 1990;29(1):3-29.

50. (MathWorks). goodnessOfFit [Internet]. R2019a Documentation. 2019 [cited 2019 Jul 10]. Available from: https://uk.mathworks.com/help/ident/ref/goodnessoffit.html

51. Schmitt EA, Flanagan DR, Linhardt RJ. Importance of Distinct Water Environments in the Hydrolysis of Poly(dl-lactide-co-glycolide). Macromolecules. 1994;27(3):743-8.

52. Edge M, Allen NS, Jewitt TS, Horie C V. The inhibition of oxidative and hydrolytic degradation pathways in archival cellulose-triacetate base cinematograph films. Polym Degrad Stab. 1990;29(1):31-48.

53. Bigourdan J, Reilly JM. Effectiveness of Storage Conditions in Controlling the Vinegar Syndrome: Preservation Strategies for Acetate Base Motion-Picture Film Collections. In: Aubert M, Billeaud R, editors. Image and Sound Archiving and Access: the Challenges of the 3rd Millenium, proceedings of the Joint Technical Symposium. Paris; 2000. p. 14-34.

54. Allen NS, Edge M, Appleyard JH, Jewitt TS, Horie CV, Francis D. Degradation of cellulose triacetate cinematographic film: Prediction of archival life. Polym Degrad Stab. 1989;23(1):43-50.

55. Bigourdan J-L. Stability of Acetate Film Base: Accelerated-Aging Data Revisited. J Imaging Sci Technol. 2006;50(5):494-501.

56. Nishimura D. Strategies for the storage of cellulose acetate film. AIC News. 2015;40(6):1-5.

57. Shenton H. Addressing Cellulose Acetate Microfilm from a British Library perspective. Lib Q. 2005;15(2).

58. Field C. Forum, Round Table and Vinegar: Managing the Cellulose Acetate Microfilm Challenge. Lib Q. $2005 ; 15(2)$. 
